\title{
AKHLAK YANG BURUK DALAM PERSPEKTIF PENDIDIKAN ISLAM SERTA UPAYA PENANGGULANGANNYA
}

\author{
Ahmad Zuhdi \\ Institut Agama Islam Negeri (LAIN) Kerinci \\ email: ahmadzuhdi@gmail.com
}

\begin{abstract}
Morals are generally all forms of actions carried out on the willing. The willingness of someone if it is contrary to the principles of Islamic teachings, Based on Al-Qur'an and the Hadith of the Prophet Muhammad, then the behaviours is classified as a bad character. The bad character that is done by someone is happened because of his inability to control his lust, because his lust has taken control of him. Efforts to establish and maintain bad behaviour, it is necessary to sow the taste and strength of brotherhood, so that each individual has a bond between one another. In addition, each individual needs to study Moral Science which aims to provide guidance to humans in knowing good or bad deeds.
\end{abstract}

Keyword: Bad Morals, Islamic Education, Handling 


\section{PENDAHULUAN}

Akhlak yang senantiasa melekat pada prilaku seseorang menurut norma-norma atau penilaian yang diberikan sesuai perbuatan yang dilakukan tersebut. Perbuatan itu ditentukan pula dengan kriteria-kriteria yang jelas apakah baik atau buruk. Akhlak secara umum merupakan segala bentuk perbuatan yang memiliki ciri-ciri sebagaimana disebutkan di atas, yaitu perbuatan yang dilakukan atas kehendak dan kemauan. Kehendak dan kemauan yang dilakukan seseorang bila bertentangan dengan asas-asas ajaran Islam, yakni al-Quran dan Hadis Rasulullah SAW, maka tentu prilaku tersebut tergolong pada akhlak yang buruk. Prilaku yang buruk yang dilakukan oleh seseorang sebenarnya adalah karena ketidaksanggupan dirinya mengontrol nafsunya, karena nafsunya sudah menguasai dirinya, disamping pemehaman dan pengertian baik baginya tidak jelas, sehingga perbuatan buruklah yang dianggapnya baik. Padahal prilaku buruk sebenarnya sangat membahayakan bagi dirinya dan juga masyarakat. Lemahnya kesadaran bagi seseorang yang melakukan perbuatan keji tentu akan memberikan danpak yang lebih buruk lagi. Semakin lama manusia itu membiarkan dirinya dikuasai syaitan, maka semakin jauhlah ia dengan Allah SW'T, maka semakin tebal pula hijab-hijab nafsu dihatinya, seterusnya menghilangkan harapan manusia itu untuk mema'rifatkan dirinya dengan Allah SWT (Azwan, 1993:15).

Dalam Islam, manusia sebenarnya merupakan makhluk yang sempurna dan berbeda dengan makhluk lain. Manusia diberi kemuliaan dan kelebihan, sebagaimana disebutkan dalam firman Allah SWT :

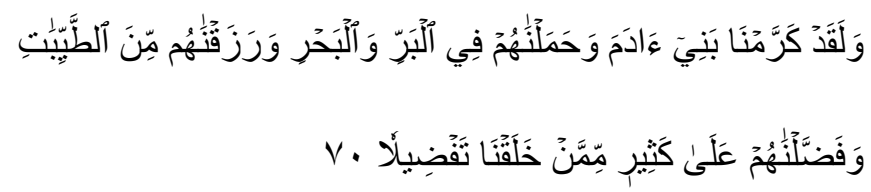

Maksudnya "Dan sesungguhnya telah Kami muliakan anak-anak Adam, Kami angkut mereka di daratan dan di lautan, Kami beri mereka rezeki dari yang baik-baik dan Kami lebihkan mereka dengan kelebihan yang sempurna atas kebanyakan makhluk yang telah Kami ciptakan"'(QS. Al-Isra' $16: 70)$ 
Pada ayat yang lain disebutkan pula :

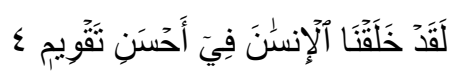

Maksudnya "sesungguhnya Kami telah menciptakan manusia dalam bentuk yang sebaikbaiknya"(QS. $95: 4)$

Demikian halnya dengan kajian tentang akhlak semakin tumbuh menjadi suatu ilmu yang berdiri sendiri, yaitu ilmu yang memiliki ruang lingkup pembahasan yaitu, tujuan, rujukan aliran dan para tokoh yang mengembangkannya. Pelbagai aspek yang terkandung dalam akhlak ini kemudian membentuk satu kesatuan yang saling berkaitan dan membentuk suatu ilmu.

\section{PEMBAHASAN}

\section{Definisi Akhlak yang Buruk}

Sebelum memberikan definisi tentang hal yang berkaitan dengan akhlak buruk, perlu diketahui bahawa tiori yang pernah dikemukakan oleh Lambrosso dalam Lari (2006:33) dan para pengikutnya yang percaya akan adanya manusia yang terlahir sebagai penjahat. Pendapatnya ini telah ditolak oleh para ahli sesuai dengan bidangnya. Seperti Alexis Carrel, seorang sarjana kebangsaan Prancis, yang menyatakan bahwa, manusia yang terlahir sebagai penjahat, seperti dikemukakan oleh Lambrosso tidaklah benar. Yang ada adalah orang yang terlahir dalam keadaan kurang sempurna dan kemudian menjadi penjahat. Pada kenyataannya, kebanyakan penjahat adalah orang-orang normal. Bahkan bias jadi ia lebih pandai dari para polisi dan hakim (Lari, 2006:33).

Oleh karenanya, Al-Ghazali secara cemerlang membedakan beberapa hal mengenai keburukan akhlak (Mahjudin, 1991:41) yakni :

a. Keburukan akhlak yang timbul karena ketidaksanggupan seseorang mengendalikan nafsunya, sehingga pelakunya disebut al-jabil ( ال خاهلى ).

b. Perbuatan yang diketahui keburukannya, tetapi ia tidak bisa meninggalkannya karena nafsunya sudah menguasai dirinya, sehingga pelakunya disebut al-jabil al-dhollu ( ال جاهل

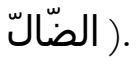

c. Keburukan akhlak yang dilakukan oleh seseorang, karena pengertian baik baginya sudah kabur, sehingga perbuatan buruklah yang dianggapnya baik. Maka pelakunya disebut al-jabil

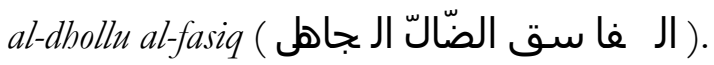


d. Perbuatan buruk yang sangat berbahaya terhadap masyarakat pada nya, sedangkan tidak terdapat tanda-tanda kesadaran bagi pelakunya, kecuali hanya kekhawatiran akan menimbulkan pengorbanan yang lebih hebat lagi. Orang yang melakukannya disebut al-jahil al-dhollu al-fasiq al-syarir ( الشّرير ال فا سق الضّالّ ال الهاه ).

Apa yang dikemukakan oleh Al-Ghazali, diatas dengan pembagian secara rinci keburukan akhlak hal ini menggambarkan bahwa eksistensi ajaran Islam menghalalkan bagi penguasa/pemimpin untuk memberikan hukuman mati bagi pelakunya, bila metode-metode yang sederhana tidak diindahkan oleh umat atau masyarakat secara kolektif. Tujuannya adalah agar perilaku yang merusak dan mencemarkan tersebut tidak menimbulkan volusi universal. Yang meresahkan masyarakat, bangsa dan negara.

\section{Faktor Penyebab Akhlak Buruk}

Dalam tafsir Tematik (Ali, 1997:619) dijelaskan bahwa, maksiat dan dosa merupakan prilaku manusia dalam keseharian mereka. Manusia biasa tidak terlepas dari prilaku dosa setiap harinya, baik dosa kecil maupun dosa besar, hanya prekuuensinya yang berbeda, kecuali para Nabi, karena mereka terpelihara dari dosa (Lajnah Pentashihan Mushaf al-Quran. 2002:151).

Muncul dan lahirnya sikap yang tidak terpuji saat sekarang, salah satu akibat dari individu yang menerima budaya yang dating dari luar, tanpa ada usaha penyeleksian baik dan buruknya terhadap mereka. Karena mengambil suatu budaya katakanlah itu barat yang tidak sesuai dengan budaya bangsa yang budaya timur, mereka terpengaruh dengan kebiasaan yang buruk melalui berbagai pengaruh baik media elektronik, style, dan gaya hidup yang serba lebih ke modern-modernan. Disisi lain wujud pula pertumbuhan dan perkembangan teknologi yang beriringan dengan budaya membuat sebagian orang di negeri ini menyalahgunakannya dengan berbagai kemauan dan kehendak mereka sendiri.

Seyogyanya masyarakat turut cerdas dengan pertumbuhan dan perkembangan teknologi dan mampu menapis segala yang menjerumuskan mereka dari budaya yang dapat merusak jati dirinya, mereka dapat memilih dan memilah mana yang baik dan mana pula budaya, teknologi dan lain sebagainya yang bermanfaat dan memiliki kemaslahatan yang positif.

\section{Dampak Akhlak Buruk}

Hamka mengemukakan; kita ini manusia, terjadi daripada jasmani, rohani dan nafsunya; tubuh, nyawa dan nafsu. Kita bukan Malaikat yang semata-mata Rohaniat. Kitapun bukan Iblis yang semata-mata api yang penuh kenafsuan. Tetapi kitapun bukan semata-mata 
binatang. Sebab kita dapat menimbang mana yang baik, mana yang buruk, mana yang manfaat dan mana yang berbahaya (Hamka, 1983:36). Kalau terus menerus berbuat maksiat tandanya luka sudah, dia tidak takut lagi kepada azab siksa Allah. Dia sudah diperintah oleh hawa nafsunya dan dilepaskannya dirinya daripada perintah Allah (Hamka, 1983:48).

Dalah salah satu hadis, disebutkan oleh Rasulullah saw, bagaimana menghindari keburukan akhlak, serta memelihara kejahatan yang dilahirkan oleh nafsu

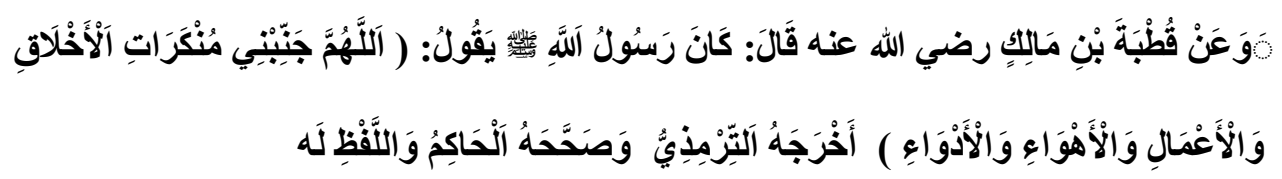

Maksudnya "Dari Quthbah Ibnu Malik Radliyallaahu 'anhu bahwa Rasulullah Shallallaahu 'alaihi wa Sallam bersabda: "Ya Allah jauhkanlah diriku dari kejelekan akhlak perbuatan hawa nafsu dan penyakit." Riwayat Tirmidzi. Hadits shahih menurut Hakim dan lafadz ini menurut riwayatnya" (Al-Hafidh Imam Ibnu Hajar al-Asqalany, 2008).

Allah SWT dalam firmanNya :

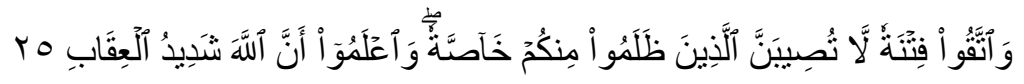

Maksudnya : "Dan peliharalah dirimu dari pada siksaan yang tidak khusus menimpa orangorang yang zalim saja di antara kamu. Dan ketahuilah bahwa Allah amat keras siksaanNya"(QS. Al-Anfal $8: 25)$

\section{Upaya Penanggulangannya}

Saatnya bagi ummat Islam untuk lebih terbuka lagi dalam mencari ilmu agama tanpa fanatik kepada golongan atau guru tertentu karena ummat sudah semakin dewasa dan sarana informasi telah berkembang pesat sehingga tidak ada alasan lagi bagi ummat Islam untuk mengatakan "tidak tahu", akan tetapi yang lebih tepat adalah "tidak mau tahu". Ikhlas dalam menjelaskan suatu permasalahan dengan niat supaya ummat beribadah kepada Allah dengan benar dan baik sesuai tuntunan Nabi Muhammad SAW para Sahabat Beliau. Berdakwah mengajak manusia kepada Allah dan RasulNya agar selamat di dunia dan di akhirat, dengan penyertaan perubahan sikap dan perilaku yang juga dapat dijadikan rujukan dan diteladani bagi yang lain (Zuhdi, 2016:27). Bukan mengajak manusia kepada dirinya, kelompoknya, golongannya atau kepentingannya, melainkan sesuai dengan apa yang telah diperintahkan oleh Yang Maha Kuasa. Belajar ikhlas dan berlapang dada dalam menyikapi perbedaan pendapat 
selama masih dalam koridor. Sunnah saling menghormati, menghindari menfitnah dan memprovokasi karena dalam al-Quran telah disebutkan bahwa umat Islam semua bersaudara dan semoga semua pada akhirnya sama-sama masuk surga, meskipun disisi lain senantiasa ada perbedaan, termasuk amalan dan ibadah Sunnah (Zuhdi, 2016:88).

Usaha untuk membentuk dan memelihara agar perilaku buruk tidak berkembang, maka perlu disemai rasa dan kekuatan persaudaraan, sehingga setiap individu memeliki ikatan antara yang satu dengan yang lain. Islam telah mengajarkan prinsip-prinsip tersebut, sebagaimana disebutkan dalam hadis Nabi Muhammad saw.

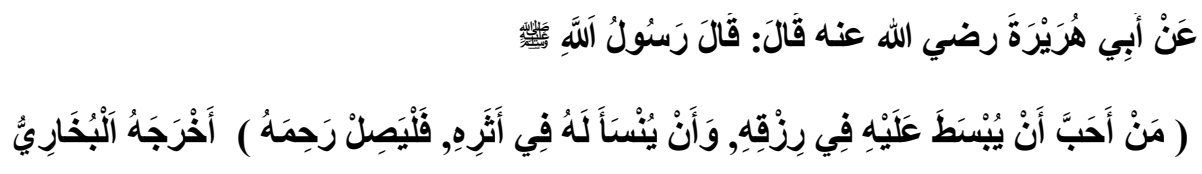

Maksudnya : "Dari Abu Hurairah Radliyallaahu 'anhu bahwa Rasulullah Shallallaahu 'alaihi wa Sallam bersabda: "Barangsiapa ingin dilapangkan rizqinya dan dipanjangkan umurnya, hendaknya ia menghubungkan tali kekerabatan." Riwayat Bukhari (Al-Hafidh Imam Ibnu Hajar al-Asqalany, 2008)

Selain itu, juga disebutkan dalam hadis lain, dari Abu Hurairah r.a, dari Nabi saw beliau bersabda; tujuh golongan dilindungi Allah dibawah lindunganNya, waktu tidak ada lindungan selain lindunganNya (Hamidy et al, 1992:98):

1. Imam (Kepala Pemerintahan) yang adil

2. Pemuda yang dalam masa mudanya beribadat kepada Allah

3. Orang yang menyebut (mengingati) Allah ketika sendirian, lalu menetes air matanya

4. Laki-laki yang tergantung hatinya di masjid (beribadat)

5. Orang yang berkasih saying karena Allah semata-mata

6. Laki-laki yang dirayu oelh seorang perempuan bangsawan cantic, tetapi dia mengatakan (menolak) "Sesungguhnya saya takut kepada Allah"

7. Orang yang bersedekah dan disembunyikan, sehingga tangan kirinya tidak mengetahui apa yang diperbuat (diberikan) oleh tangan kanannya.

Mengetahui akhlak yang buruk serta bahaya-bahaya yang akan ditimbulkan darinya, menyebabkan orang enggan untuk melakukannya dan berusaha menjauhinya. Orang yang demikian pada akhirnya akan terhindar dari berbagai perbuatan yang dapat membahayakan dirinya. Dengan demikian secara ringkas dapat dikatakan bahwa Ilmu Akhlak bertujuan untuk memberikan pedoman atau penerangan bagi manusia dalam mengetahui perbuatan yang baik 
atau yang buruk. Terhadap perbuatan yang baik ia berusaha melakukannya, dan terhadap perbuatan yang buruk ia berusaha untuk menghindarinya.

\section{PENUTUP}

Manusia semestinya dapat memahami bahwa ia ciptakan memiliki tujuan hidup. Dengan mengawali memahami keberadaannya dalam sistem penciptaan. Sebagaimana juga alam semesta diciptakan Allah bukan tiada tujuan. Manusia adalah salah satu dari penciptaan alam semesta, dimana alam yang ciciptakan tersebut adalah untuk suatu tujuan. Sebagaimana yang dijelaskan dalam firman Allah SWT dalam surat al-Zariyat ayat 56, Nampak jelas fungsi dan tujuan manusia diciptakan oleh Allah, yakni untuk mengabdikan diri dengan ketentuan dan aturan yang benar. Hal ini untuk menjelaskan kepada manusia bahwa dalam proses dan sistem penciptaannya adalah sebagai hamba Allah SWT. Tentu berkaitan dengan peran yang mesti dipahami oleh manusia untuk melakukan ibadah kepada Allah SWT.

Kegiatan dan perbuatan yang melekat pada manusia tersebut menunjukkan bahwa perbuatan ibadah tidak terbatas pada shalat, puasa, zakat yang biasa disebut ibadah mahdah, tetapi ibadah meliputi segala tindak tanduk serta perbuatan dalam menjalankan peranannya sebagai manusia di muka bumi yaitu diberikan kepercayaan sebagai khalifah Allah. Tindakan moral yang baik dan mulia, merupakan wujud ibadah yang meliputi keseluruhan kegiatan manusia dalam hdup di dunia ini, baik kegiatan duniawi sehari-hari, bila aktifitas itu dilakukan dengan sikap batin serta niat pengabdian dan penghambaan diri kepadaNya.

\section{REFERENSI}

Abudinnata. (2014). Akblak Tasawnf dan Karakter Mulia. Jakarta: rajawali Pers.

Abdullah, M Yatimin. (2007). Studi Akblak dalam Perspektif Islam. Jakarta: Amzah.

Abdul Aziz bin Fathi As Sayyid Nada. (2008). Ensiklopedia Etika Islam: Begini Semestinya Muslim Berperilaku, terj Muhammad Isnaini dkk. Jakarta: Maghfirah Pustaka.

Al Ghazali, Muhammad. (1995). Akblak Seorang Muslim, terj. Abu Laila \& muhammad Tohir. Bandung: PT. Alma'arif.

Al-Hafidh Imam Ibnu Hajar al-Asqalany. (2008). Bulugul Maram min Adilatil Abkaam, trj. Tasik Malaya: Pustaka al-Hidyah.

Al Hasyimi, Abdul Mun’im. (2009).Akblak Rasul Menurut Bukhari \& Muslim. Jakarta: Gema Insani.

Azwan, Hal. (1993). Rahasia Mengenal Diri, Selangor D.E, Cita Khidmat.

Hamka. (1983). Iman dan Amal Saleh. Kuala Lumpur: Pustaka Melayu Baru. 
Mahjudin. (1991). Kuliah Akblak-Tasawuf. Jakarta: Kalam Mulia.

Lajnah Pentashihan Mushaf al-Quran. (2012). Tafsir al-Quran Tematik, Spritualitas dan Akblak. Jakarta: Aku Bisa.

Lukman Ali. (1997). Kamus Besar Bahasa Indonesia. Jakarta: Balai Pustaka.

Salam, Burhanuddin. (2002). Etika Sosial: Asas Moral dalam Kebidupan Manusia. Jakarta: Rineka Cipta.

Sayyid Mujtaba Musawi Lari. (2006). Etichs and Spritual Grawth, trj. Ahsin Muhammad dan Ruswan D. Bandung: Pustaka Hidayah.

Sjarkawi. (2008). Pembentukan Kepribadian Anak: Peran Moral, Intelektual, Emosional, dan Sosial sebagai Wujud Integrasi Membangun Jati Diri. Jakarta: Bumi Aksara.

Zainuddin Hamidy, et al. (1992) Terjemah Hadist Shabih Bukhari, 1815, jilid I-IV. Jakarta: Widjaya.

Zuhdi, Ahmad. (2016). Dakwah Sebagai Ilmu dan Perspektif Masa Depannya. Bandung: Alpabeta. 